by Lavoisier of the first of his memoirs on the theory of combustion, attention was directed to Rey's book, with the suggestion that it was perhaps unknown to the chemists of that day. Occasional references had, however, been made to it, between 1630 and 1774, in the literature of chemistry-the earliest, indeed, by no less a person than the philosopher Mersenne. A correspondence between Rey and Mersenne resulted, and this has been reproduced in this modern edition of the "Essays". Nevertheless, later references were few, a fact that Dr. D. McKie, in his introduction to the volume, suggests may perhaps be attributed to scarcity of copies of the book itself, rather than lack of appreciation of its contents. The original edition was, probably, small and intended only for circulation among the author's friends. To-day the first edition is certainly very rare, only seven copies having been traced. Since 1774 a number of reprints and translations have appeared, but these too are not now easily obtainable.

The new edition reproduces the original text in facsimile, so that scholars may now read it in the original French, and the value of this reprint is greatly enhanced by Dr. McKie's introductory essay. In addition to the few facts known about Rey's life, the introduction contains bibliographical details of the earlier editions of the "Essays" and a critical appreciation of the work itself, and such influence as it may have had on the development of chemistry.

Much of the information contained in this essay is derived from sources not easily accessible, if at all, to the average student. Readers of Dr. McKie's studies in the history of chemistry need scarcely be told that he has been at great pains to seek it out, to check its accuracy, and to assemble it in readable form. His attractively produced reprint of the "Essays" should take rank as the definitive edition, at any rate so far as English-speaking readers are concerned, and as such it will be welcomed by librarians and students of the history of chemistry.

V. A. EyLES

\section{BIOLOGICAL PHILOSOPHY}

\section{Problems of Life}

An Evaluation of Modern Biological Thought. By Ludwig von Bertalanffy. Pp. xi +216 . (London : Watts and Co., Ltd., 1952.) 25s. net.

"r WHE future historian of our times," says Dr. L. von Bertalanffy towards the end of this book (p. 194), "will note as a remarkable phenomenon that since the time of [after] the First World War, similar conceptions about Nature, mind, life and society, arose independently, not only in different sciences, but also in different countries. Everywhere we find the same leading motifs; concepts of organization showing [that is, the concept of an organization which manifests] new characteristics and laws at each level, those of [that is, the concept of] the dynamic nature of [reality], and the [that of] antitheses within it". That the philosophy of organic naturalism has in general, during the past half-century, risen to the status of a dominant world outlook among men of science is, indeed, undeniable. The ideas of Whitehead, at least in their broader aspects, have been almost universally accepted; the controversy between vitalism and mechanism, which in the twenties was still flourishing, no longer attracts any attention ; the Gestalt conception in psychology and physiology has proved itself. The problem now before scientific workers is the practical one of elucidating the relations between the 'organisms' at the atomic and molecular level, and the organic form of living things which they compose. Dr. von Bertalanffy is one of the foremost living theoretical biologists, Austrian by origin, who has been associated with the study and exposition of organic naturalism since his first publication in 1926. In recent years he has become what one might describe as 'the Woodger of Canada'.

The plan of the book begins by contrasting the conceptions of organic naturalism with the classical alternative. It then considers levels of organization, the present position of the cell theory, and the question of supra-individual organisms. This is followed by detailed exemplifications from experimental morphology and neurophysiology, after which such hypotheses as the biological magnification of non-statistical microphysical events are discussed. The work ends with the demand for a new general theory of systems, and the promise that new logico-mathematical formulations suitable for organic phenomena have been devised and will be presented in a further book (p. 199). The present monograph is highly recommendable for younger scientists who have not been able to follow, during the past three decades, the development of the points of view now generally accepted.

This is not to say that one can lay down the book without certain feelings of dissatisfaction. In the first place, the translator has failed to rise to the level of the German original, published in Switzerland in 1949. It takes a certain acuity as well as goodwill to penetrate through his English to the value within it. For example, upon a single page (p. 171) the reviewer noted the following necessary substitutions: "methodological" for "methodical", "enunciate" for "enounce", "spiritual" for "psychic", "myth or" for "mythical", and "illusory" for "illusive". The text is full of sentences of this kind: "It is the peculiar hybrid position between science and poetry by which vitalism is sapped". If the whole book could be re-written in English, its value would be doubled. Indeed, in order to quote the passage used at the beginning of this review, the reviewer had to add elucidations. There are also a few irritating mistakes, such as the eternal confusion of J. B. S. Haldane with his father (p. 197).

But a more basic criticism is that Dr. von Bertalanffy, if intending to cover the whole field of organic philosophy, ought to have done more justice to Whitehead, even if Smuts and Lloyd-Morgan were treated shortly. He may have felt that this would have been to go beyond the bounds of that theoretical biology about which he wanted to talk; but even within them, there are certain fascinating subjects, such as the relation between thermodynamic theory and biological evolution, which are scarcely touched upon. However, there are obvious limits to what can be done in two hundred pages of fairly large type; and this book should in any event take its place upon the shelves of all biological libraries, both private and public. If it reached a few physicochemical ones also, that would be all to the good. JosEPH NEEDHAM 